\title{
Economia, saúde e políticas do verdadeiro nas declarações de Bolsonaro durante a pandemia de COVID-19 no Brasil
}

\author{
Economy, health and politics of truth in Bolsonaro's statements during the \\ COVID-19
}

\author{
Karla Saraiva \\ Universidade Luterana do Brasil | Av. Farroupilha, 8001 - Canoas, RS| Brasil | \\ http://orcid.org/ 0000-0002-2105-0619| profa.karla.saraiva@gmail.com

\begin{abstract}
Luiz Felipe Zago
Universidade Federal do Rio Grande do Sul | Av. Paulo Gama, 110 - Porto Alegre, RS| Brasil | http://orcid.org/ 0000-0003-4453-5982 | luizfelipezago@gmail.com
\end{abstract}

Fechas | Recepción: 14/01/2021 | Aceptación: 09/03/2021

Resumo

O artigo tem por objetivo analisar como as declarações do Presidente Bolsonaro estabeleceram determinadas políticas do verdadeiro em relação à pandemia de COVID19 no Brasil. O material de análise é constituído por três pronunciamentos, realizados quando o país iniciava o isolamento social, e 45 reportagens com declarações do Presidente publicadas no portal GaúchaZH, de Porto Alegre, entre março e julho de 2020. Foram extraídos excertos que mostram as opiniões e crenças de Bolsonaro em relação aos eixos discursivos "saúde" e "economia" no âmbito da pandemia. A partir desse material foram criadas duas categorias analíticas: "mercado acima de todos", com declarações relacionadas à economia, e "cloroquina acima de tudo", com declarações relacionadas à saúde. $\mathrm{O}$ conjunto de procedimentos metodológicos apoiam-se na análise de discurso em Michel Foucault, que investiga os modos como poder e verdade se articulam naquilo que é dito. Mostra-se que o Presidente brasileiro enunciou a verdade neoliberal, desocultando o mercado como organizador fundamental do seu discurso durante a pandemia no Brasil. Essa verdade do mercado

\section{Abstract}

The article aims to analyze how President Bolsonaro's statements established certain politics of truth regarding the COVID-19 pandemic in Brazil. The analysis material consists of the content of three pronouncements, made when the country started social isolation, and 45 journalistic reports with statements made by the President, published on the GaúchaZH portal, from Porto Alegre, between March and July, 2020. Excerpts were extracted showing Bolsonaro's opinions and beliefs in relation to the discursive axis of "health" and "economics" in the context of the pandemic. From this material, two analytical categories were created: "maket above all", with statements related to economy, and "chloroquine above everything", with statements related to the economy. The set of methodological procedures is based on the discourse analysis by Michel Foucault, which investigates the ways in which power and truth are articulated in what is said. It is shown that the Brazilian President has enunciated the neoliberal truth, unveiling the market as a fundamental organizer of his speech during the pandemic in Brazil. This market truth rests on specific conceptions of freedom and democracy: 
repousa em concepções específicas de liberdade e de democracia: individualistas, atomizadas, esvaziadas de seu caráter coletivo. Ainda, Bolsonaro apostou que a cloroquina seria a "pílula mágica" que salvaguardaria a saúde biológica da população e a saúde econômica do país. Porém, a saúde econômica foi sempre mais importante do que saúde biológica, o que sugere o desprezo pelas mortes dos cidadãos brasileiros por COVID-19. As políticas do verdadeiro nas declarações de Bolsonaro são políticas de morte.

Palavras-chave: análise de discurso, covid-19, economia, saúde, política. individualistic, atomized, emptied of its collective character. Still, Bolsonaro bet that chloroquine would be the "magic pill" that would safeguard the biological health of the population and the economic health of the country. However, economic health has always been more important than biological health, which suggests contempt for the deaths of Brazilian citizens by COVID-19. The politics of truth in Bolsonaro's statements are politics of death.

Keywords: discourse analysis, covid-19, economy, health, politics.

\section{INTRODUÇÃO - FRAGMENTOS DA PANDEMIA DE COVID-19}

O ano de 2020 recém começava e o mundo foi surpreendido com um vírus altamente transmissível: o SARS-CoV-2. Os primeiros casos foram detectados no início de janeiro, na China. Neste mesmo mês, o vírus já chegara aos Estados Unidos e à Europa. No início de fevereiro, o Ministério da Saúde do Brasil confirmou os primeiros casos relacionados com viajantes que retornaram ao país já contaminados. Em poucas semanas, o vírus se espalhou pelo país, e intensificou-se a contaminação comunitária.

Gradativamente, medidas sanitárias orientando para o isolamento social foram tomadas em grande parte do mundo, com maior ou menor rigor e agilidade. Nos Estados Unidos, o apoio de Donald Trump ao isolamento social foi muito reticente. Jair Bolsonaro, Presidente do Brasil, tratou com desprezo os efeitos da pandemia. Para ele, o país não deveria parar os negócios, pois, como repetiu inúmeras vezes e analisaremos a seguir, a fome mataria mais do que 0 COVID-19.

Ao chegar no Brasil, a pandemia de COVID-19 também expôs as tensas relações do Presidente Bolsonaro com a mídia tradicional do país, composta por empresas de comunicação multimeios privadas. Estas assumiram a cobertura da pandemia baseando-se em dados fornecidos pelas Secretarias de Saúde de estados e municípios, na medida em que o governo federal dificultava a divulgação de estatísticas. Essa cobertura indicava o aumento exponencial dos casos de COVID-19 no Brasil e a necessidade de adoção de estratégias duras de prevenção ao vírus, sob pena de haver o colapso do sistema de saúde brasileiro. Em um crescente antagonismo, Bolsonaro e a mídia tradicional brasileira passaram a disputar narrativas sobre a gravidade, as consequências e os modos de tratar e prevenir a infecção respiratória causada pelo coronavírus.

Em meio a essa disputa, o Presidente deu várias declarações que expressavam a posição oficial do governo brasileiro sobre a pandemia e como enfrentá-la. A mídia tradicional brasileira repercutiu as declarações e ações do Presidente, que figuraram como manchetes de jornais, chamadas de telejornais e títulos de matérias jornalísticas em vários veículos de comunicação do país. Nesse sentido, inobstante a esquiva comunicação política do governo Bolsonaro, a 
mídia tradicional brasileira registrou e divulgou as falas desse ator político controverso durante um período conturbado.

Assim, este artigo tem por objetivo analisar como as declarações do Presidente Bolsonaro estabeleceram determinadas políticas do verdadeiro em relação à COVID-19 no Brasil. 0 material de análise consiste na transcrição de três pronunciamentos, realizados quando o país iniciava o isolamento social, e 45 reportagens publicadas no portal $G a u ́ c h a Z H^{1}$, de Porto Alegre. O recorte temporal definido para seleção foi entre 16 de março de 2020, quando as primeiras normativas públicas relativas ao isolamento social foram apresentadas, até dia 15 de julho de 2020, logo após o anúncio da contaminação de Bolsonaro pelo vírus. Durante a produção deste artigo, o Presidente fez uma manifestação homofóbica sobre o enfrentamento do vírus no dia 10 de novembro. Devido à repercussão desta declaração e aderência à proposta aqui apresentada, decidimos incluir esta matéria na empiria.

Na seção seguinte, apresentamos a metodologia adotada, baseada na análise de discurso em Michel Foucault. A seguir, apresentamos a fundamentação teórica a partir dos conceitos de discurso, verdade e políticas do verdadeiro, também a partir de Michel Foucault e comentadores. Nas duas seções subsequentes, desenvolvemos as análises das enunciações do Presidente brasileiro a partir de dois eixos discursivos, "economia" e "saúde", nomeando as categorias daí oriundas de Mercado acima de todos e Cloroquina acima de tudo².

\section{PROCEDIMENTOS METODOLÓGICOS}

$\mathrm{O}$ arquivamento das matérias jornalísticas iniciou-se no mês de abril de 2020. Em 24 e 31 de março e 8 de abril, o Presidente realizou três pronunciamentos em cadeia nacional de TV defendendo seu posicionamento em relação à crise sanitária. A transcrição dessas falas foi o primeiro elemento do material empírico.

Ainda, o Presidente manifestou-se com muita frequência sobre a pandemia utilizando diversas estratégias: declarações à imprensa; declarações a seus apoiadores em manifestações populares diversas; postagens em redes sociais. Para recolher suas declarações, escolhemos um jornal reconhecido nacionalmente pelo fato de haver, na prática jornalística, a publicação diária de informações devidamente apuradas. Escolhemos selecionar as matérias jornalísticas de um jornal da mídia tradicional brasileira apostando na função mediadora que a imprensa exerce entre as várias instituições sociais - algo que o Presidente parece contestar (Castilho, 2019; 2020). Nossa escolha foi pelo Jornal Zero Hora, com a quinta maior circulação no país ${ }^{3}$.

A partir da escolha do veículo, selecionamos 45 matérias usando como critério o uso, nas reportagens, de falas diretas do Presidente. Das matérias foram extraídos excertos que mostram as opiniões e crenças de Bolsonaro em relação aos eixos discursivos "saúde" e "economia" no âmbito da pandemia. A partir daí, criamos as duas categorias analíticas deste artigo. Para cada uma das categorias, construímos um arcabouço analítico, mobilizando aqui os excertos que nos pareceram de maior interesse, tendo em vista as limitações do artigo. Os

\footnotetext{
${ }^{1}$ Portal Gaúcha ZH. Disponível em https://gauchazh.clicrbs.com.br/. Acesso 06 jan. de 2021. O portal é a versão digital do jornal Zero Hora, aquele de maior circulação na cidade de Porto Alegre, e existe desde 2017.

2 Trata-se de uma referência ao slogan da campanha que elegeu Bolsonaro: "Brasil acima de tudo, Deus acima de todos". Disponível em https://bit.ly/35GCiSi. Acesso 06 jan. de 2021.

3 Portal Meio\&Mensagem. Disponível em https://bit.ly/2KdSmTN. Acesso 06 jan. de 2021.
} 
excertos serão analisados pela perspectiva da análise de discurso foucaultiana, que será apresentada na seção seguinte.

\section{DISCURSO, VERDADE E POLÍTICAS DO VERDADEIRO}

Com base em Michel Foucault (2000, 2009), uma análise de discurso jornalístico procura evidenciar os modos como poder e verdade se articulam naquilo que é dito, forjando a realidade de fatos que são aparentemente narrados de forma neutra. Este é um dos aspectos do funcionamento do jornalismo na contemporaneidade: "um modus operandi que finda por Ihe chancelar uma posição estratégica na produção e difusão de certos discursos, bem como no arrefecimento ou, no limite, rarefação de outros discursos possíveis" (Do Val y Aquino, 2013, p. 95-96). Do Val e Aquino (2013) sugerem que o conjunto de veículos jornalísticos se orienta pela visibilidade: "quanto mais informação, mais fácil seria desvendar a suposta integralidade da verdade, em suas diferentes facetas" (Do Val y Aquino, 2013, p. 96). Entretanto, essa aparente mimese do fato narrado com a verdade é o produto de um regime de veridicção do real (Do Valy Aquino, 2013). A verdade como efeito discursivo é algo fundamental para o jornalismo, na medida em que o modo como aquilo que é dito arregimenta elementos que constroem o que funcionará como realidade. "Os procedimentos que asseguram os efeitos de verdade são legítimos para o jornalismo porque estão baseados em estratégias que buscam a confiabilidade" (Benetti, 2008, p. 25), isto é, a confiança construída enquanto pacto de inteligibilidade entre leitores e profissionais, algo que assegura a credibilidade do discurso jornalístico. "Os enunciados jornalísticos apresentam-se, portanto, como elos de uma corrente de enunciação histórica e socialmente organizada, inserida em regimes de verdade preexistentes que renascem no próprio ato daquela enunciação" (Do Val y Aquino, 2013, p. 99).

De acordo com as teorizações de Foucault (2000, 2009), poder e saber formam um par indissociável. Não há exercício de poder sem saberes e, nessa relação, está em jogo a produção da verdade. Para Foucault, é por meio de práticas discursivas que se constituem as políticas de verdade de uma sociedade,

isto é, os tipos de discurso que ela acolhe e faz funcionar como verdadeiros; os mecanismos e as instâncias que permitem distinguir os enunciados verdadeiros dos falsos, a maneira como se sanciona uns e outros; as técnicas e os procedimentos que são valorizados para a obtenção da verdade; o estatuto daqueles que têm o encargo de dizer o que funciona como verdadeiro. (Foucault, 2000, p.12)

Compreender que políticas de verdade são construções sócio-históricas expõe o caráter arbitrário que as constitui. Para Foucault (2000, p. 12), "a verdade é deste mundo; ela é produzida nele graças a múltiplas coerções e nele produz efeitos regulamentados de poder".

Por outro lado, o mesmo autor (Foucault, 2014) mostra que, para o exercício do poder político, não bastam os conhecimentos úteis, como no caso das sociedades modernas e contemporâneas, os dados estatísticos sobre a saúde da população, sobre o funcionamento da economia e das atividades produtivas, ou sobre a situação fiscal do país. Segundo ele, são necessárias manifestações de verdade ritualizadas que possam fundar e legitimar o exercício do poder, manifestações estas que vão no sentido de revelar uma suposta verdade oculta (Foucault, 2009). Como veremos a seguir, Bolsonaro instituiu rituais de manifestação da 
verdade em suas enunciações sobre a pandemia, caracterizados por uma oposição à ciência e por um enfrentamento suicida do vírus. E é por esta razão, visando a marcar um certo distanciamento das estratégias que separam o verdadeiro do falso, em direção a estratégias que pretendem desvelar verdades ocultas, que preferimos utilizar aqui o conceito de políticas do verdadeiro, e não o de políticas de verdade.

De acordo com Stanley (2020), nos últimos anos diversos países foram assolados por um nacionalismo de extrema-direita que ele identifica como fascismo. No Brasil, o Presidente Bolsonaro vem encarnando a figura desse líder nacionalista populista e elegeu-se em 2018 com uma retórica que decalca as características do fascismo arroladas por este autor quase integralmente. Sua campanha foi estruturada enaltecendo sua carreira no exército, associando-a a benefícios que os militares teriam trazido para o país durante uma ditadura ocorrida na segunda metade do século 20. Posicionava-se como o candidato capaz de combater malefícios produzidos por governos de esquerda que o antecederam: a corrupção; a dissolução de hierarquias sociais baseadas em raça, gênero e sexualidade, ameaçando a constituição das famílias; a vitimização do homem branco, heterossexual, que estaria sofrendo preconceitos por sua condição; uma fixação em uma retórica sexual, principalmente no campo da Educação, acusando as escolas de incitarem a ideologia de gênero; o repúdio a políticas de inclusão social. Tudo isso sustentado por correntes digitais que disseminam notícias falsas e teorias da conspiração de cunho anti-intelectual e anticientífico.

Essas características se mantiveram presentes nas declarações do Presidente brasileiro durante os primeiros meses da pandemia no país. Suas declarações foram parte de um conjunto discursivo mais amplo do governo, que englobou notas e outros documentos oficiais, que localizaram o que chamamos aqui de política do verdadeiro de Jair Bolsonaro sobre a pandemia de COVID-19. O Presidente, ocupando o cargo de máxima responsabilidade sobre o país e seus cidadãos, forjou associações entre economia, saúde e o novo coronavírus que partidarizam a doença e seu tratamento, além de explicitamente orientar-se pela preservação do mercado em detrimento das vidas.

\section{MERCADO ACIMA DE TODOS}

Os primeiros casos detectados de indivíduos infectados com coronavírus no Brasil ocorreram em final de fevereiro. Em meados do mês de março, quando a infecção já começava a se alastrar pelo país e houve a primeira morte, no dia 17, iniciaram-se as restrições a atividades econômicas. No dia 24 de março, o Presidente Bolsonaro fez um primeiro pronunciamento, anunciando seu posicionamento em relação à pandemia, que iria gradativamente ser radicalizado. Embora tenha mostrado apoio ao então Ministro da Saúde, Luiz Henrique Mandetta, já minimizava os efeitos da pandemia e destacava a necessidade de evitar o desemprego.

O doutor Henrique Mandetta vem desempenhando um excelente trabalho de esclarecimento e preparação do SUS para atendimento de possíveis vítimas. Mas, o que tínhamos que conter naquele momento era o pânico, a histeria. E, ao mesmo tempo, traçar a estratégia para salvar vidas e evitar o desemprego em massa. (Gripezinha, 24/03/2020) 
Neste mesmo pronunciamento, afirma que "a vida tem que continuar" (Gripezinha, 24/03/2020). Também neste momento, inicia-se um antagonismo com os gestores estaduais e municipais, que estavam estabelecendo restrições às atividades produtivas, visando a conter a disseminação do vírus.

O sustento das famílias deve ser preservado. Devemos, sim, voltar à normalidade. Algumas poucas autoridades estaduais e municipais devem abandonar o conceito de terra arrasada, como proibição de transporte, fechamento de comércio e confinamento em massa. (Gripezinha, 24/03/2020)

Este pronunciamento, de certo modo, lança as bases da verdade que será enunciada por Bolsonaro acerca das relações entre economia e pandemia ao longo dos meses seguintes. Como escreveu um grupo de intelectuais, "o Brasil está sendo colocado diante de uma escolha falsa: ou a morte física provável ou a morte econômica certa" (Singer et al., 2020). Na contramão do que afirmavam muitos economistas, e que podia ser observado em outros países, a economia não estava sendo derrubada pelas restrições, mas pelo próprio vírus. Como nota Carvalho (2020), as experiências de reabertura de comércio e serviços em lugares com altos índices de contaminação não foram, em geral, bem sucedidas, tendo em vista o temor dos consumidores. "A frouxidão dessas medidas e seu relaxamento prematuro adiam ainda mais a recuperação da economia" (Carvalho, 2020, p. 18).

O Presidente, entretanto, insiste na afirmação de que não deveriam existir restrições de circulação em um novo pronunciamento no dia 31 de março, sempre utilizando o argumento de manutenção do trabalho do mais vulneráveis.

Se fechamos ou limitarmos movimentações, o que acontecerá com estas pessoas, que têm que trabalhar todos os dias, e que têm que ganhar o pão de cada dia todos os dias? [...] Não me valho dessas palavras para negar a importância das medidas de prevenção e controle da pandemia, mas para mostrar que da mesma forma precisamos pensar nos mais vulneráveis. Essa tem sido minha preocupação desde o princípio. (Pronunciamento, 01/04/2020)

Bolsonaro afirma neste segundo pronunciamento que haveria "dois problemas a resolver: 0 vírus e o desemprego, que deveriam ser tratados simultaneamente" (Pronunciamento, 01/04/2020). Contudo, quando cotejadas as afirmativas acerca da saúde, conforme a seção seguinte, e estas sobre a economia, fica evidente que o foco principal é o funcionamento das atividades econômicas, afinal "o coronavírus veio, e um dia irá embora, e infelizmente teremos perdas neste caminho. Eu mesmo já perdi entes queridos no passado" (Pronunciamento, 01/04/2020). Como é possível observar, a preocupação de Bolsonaro não era a manutenção da renda, mas do trabalho e, por conseguinte, da produção. "Com isso, Bolsonaro visa ampliar apoio junto às camadas populares desprotegidas e consolidar sua relação com setores empresariais [...], que sofrerão impactos profundos do que deve ser a maior queda anual de PIB de nossa história" (Singer et al., 2020).

Se cientistas em geral posicionaram-se pela necessidade de planos para enfrentamento da crise sanitária visando a preservar vidas, Bolsonaro sugeriu que seria necessário enfrentar o vírus em um campo de batalha que seria o mercado, sem temer as consequências:

Se você não estiver trabalhando aqui vai estar de casa. Ou vão estar de férias ou vão 
estar demitidos. Essa é uma realidade. O vírus está aí, vamos ter que enfrentá-lo. Vamos enfrentar como homem, pô, não como moleque. Vamos enfrentar o vírus com a realidade, todos nós vamos morrer um dia. (Após, 29/03/2020)

Nesta cruzada pró-mercado, o apoio ao Ministro da Saúde, expresso no primeiro pronunciamento, começa a ser retirado no início de abril:

O que aconteceu por parte de uns profissionais do ministério dele, aquela histeria, aquele clima de pânico, que aconteceu há uns 40 dias. Agora, está no momento de colocar o pé no chão. Se destruir o vírus e destruir os empregos, vamos destruir o Brasil. (Bolsonaro, 02/04/2020)

Bolsonaro constrói, assim, uma narrativa de múltiplas maneiras bélica: de enfrentamento às medidas restritivas que são impostas por prefeitos e governadores; de enfrentamento pessoal com seu Ministro da Saúde; de enfrentamento ao vírus, sem temer pela saúde e pela vida. Ele próprio se coloca como um líder destemido, indo ao encontro e apoiadores e frequentando o comércio nos finais de semana. Ao ser criticado por sua exposição, responde o seguinte:

Se eu fosse perguntar para outros, que têm uma boa vida, se eu deveria ir para rua, seria quase uma unanimidade: não. Mas não existe isso, eu estou na linha de frente com os meus soldados. Sou um general, mas estou na linha de frente. Se precisar fazer de novo, farei. (Após, 29/03/2020)

As previsões catastróficas foram reforçadas pelo Ministro da Economia Paulo Guedes, que se pronunciou da seguinte forma: "não queremos correr o risco de virar uma Venezuela, não queremos correr o risco de virar nem sequer uma Argentina, que entrou em desorganização, inflação subindo, todo esse pesadelo de volta" (Bolsonaro, 07/05/2020). Uma semana depois, Bolsonaro reitera que o caos poderia se instalar no país, declarando que

Lá na frente, eu tenho falado com o ministro Fernando [Azevedo], da Defesa... os problemas vão começar a acontecer. De caos, saque a supermercados, desobediência civil. Não adianta querer convocar as Forças Armadas porque não existe gente para tanta GLO [Garantia da Lei e da Ordem]. (É guerra, 14/05/2020)

Em março de 2020, já havia uma forte pressão social para que fosse concedido auxílio às camadas mais vulneráveis da população. Tal como ocorreu em outros países, foi se conformando aqui o auxílio emergencial. Em 18 de março, o Ministro da Economia, Paulo Guedes, já anunciava a criação de um benefício de R\$2 200,00, considerado insuficiente pelo Congresso Nacional. Após o Presidente da Câmara pautar o projeto da oposição, que elevaria o valor para $\mathrm{R} \$ 500,00$, o Governo aceita conceder $\mathrm{R} \$$ 600,004 (Brasil leva, 15/04/2020). A abrangência do programa também foi ampliada pelo Congresso: enquanto a proposta original alcançaria cerca de 20 milhões de usuários (Governo, 01/04/2020), as regras aprovadas permitiram o acesso a 66 milhões (Brasil, 21/08/2020). Concebido para ser pago em três parcelas, o auxílio emergencial sofreu sucessivas extensões. Até dezembro de 2020, foram pagas cinco parcelas de $\mathrm{R} \$ 600,00$, mais quatro parcelas de $\mathrm{R} \$ 300,00$.

Inicialmente, o auxílio emergencial suscitou bastante resistência no Governo Federal, por representar um expressivo aumento da despesa pública, ameaçando o equilíbrio fiscal. Porém,

${ }^{4} \mathrm{R} \$ 600,00$ equivalem a pouco mais de meio salário mínimo brasileiro, cerca de $\$ 100$. 
o Presidente Bolsonaro logo percebeu os benefícios para sua popularidade e propôs, em seguida, um aumento para o benefício maior do que a proposta da própria oposição. A aprovação de Bolsonaro foi amplamente beneficiada pela prorrogação do auxílio emergencial. No dia 8 de junho, Bolsonaro pronuncia-se sobre o auxílio emergencial: "Nosso governo alocou centenas de bilhões de reais não só para combater o vírus, bem como para evitar o desemprego. Cada mês pago do auxílio emergencial de $\mathrm{R} \$ 600,00$ corresponde a despesa na ordem de R\$ 40 bilhões para a União" (Bolsonaro, 08/06/2020). Apesar disto, ao longo de todo ano de 2020 foi possível observar um permanente tensionamento no Governo, com a insistente preocupação do Ministro da Economia com o teto dos gastos.

De acordo com Carvalho (2020, p. 69), o benefício aprovado contribuiu tanto para o combate ao vírus, quanto para atenuar os efeitos econômicos. Segundo a autora, os benefícios sociais no Brasil têm significativos efeitos multiplicadores, tendo em vista que são utilizados quase integralmente para o consumo, alavancando a produção e gerando impostos. Portanto, a retração econômica de $5 \%$ prevista para 2020 poderia ser muito mais forte sem o auxílio emergencial. Já Giuseppe Coco (2020, p. 816) sublinha que "o continente latino-americano mostra que a eficácia das políticas e esforços para a contenção da pandemia é drasticamente limitada pelo fato de uma porção expressiva da população depender do comércio informal”. O autor continua argumentando que essa parcela da população necessita ainda movimentar-se pelo tecido urbano, usando transportes coletivos, para manter sua renda - o que impossibilita sustentar o distanciamento social por longos períodos. Diferentemente de Carvalho (2020), Coco (2020, p. 816) destaca: "o impacto do auxílio emergencial foi paradoxal: implementado com muito atraso (...), ele acabou reforçando politicamente o negacionismo presidencial e a aceleração de uma abertura geral guiada mais pelo cansaço do que pelo sucesso da contenção do vírus".

Assim, cabe notar que mesmo reconhecendo que sua aprovação foi beneficiada pelo auxílio emergencial, o Presidente não parou de instigar a abertura econômica. No dia 25 de junho, declarou que "não podemos ter aquele pavor lá de trás, que chegou junto à população e houve, no meu entender, um excesso de preocupação apenas com uma questão [saúde] e não podia despreocupar com a outra [economia]" (Bolsonaro, 25/06/2020). Já em 12 de julho, afirmou que "A realidade do futuro de cada família brasileira deve ser despolitizada da pandemia. Os números reais dessa guerra brevemente aparecerão" (Bolsonaro, 12/07/2020).

Enunciações no mesmo sentido continuaram se repetindo ao longo de 2020 . Em 10 de novembro, houve uma declaração problemática, de bastante repercussão, pelo seu caráter homofóbico:

Tudo agora é pandemia. Tem que acabar com esse negócio. Lamento as mortes, lamento, todos nós vamos morrer um dia, todo mundo vai morrer. Não adianta fugir disso, fugir da realidade. Tem que deixar de ser um país de maricas. Olha que prato cheio para a imprensa. Para a urubuzada que está aí atrás. Temos que enfrentar, de peito aberto, lutar. (Tem,10/11/2020)

Deste modo, é possível perceber que o Presidente Bolsonaro construiu uma discursividade que instiga os brasileiros a abandonarem o isolamento social e a continuarem levando suas vidas sem preocupações com o vírus. "Ao mostrar-se indiferente à tarefa de proteger os cidadãos contra a ameaça da morte, Bolsonaro rompe com o princípio basilar do pacto social e com a 
justificativa da existência do próprio Estado: a garantia do direito à vida" (Singer et al., 2020). Sua atuação em relação à pandemia, espelhando desinformação e instigando o desrespeito ao isolamento social, o torna responsável por parte considerável das mais de 200.000 vidas ceifadas pelo vírus no Brasil, até janeiro de 2021.

\section{CLOROQUINA ACIMA DE TUDO}

Nos três pronunciamentos oficiais de Bolsonaro, realizados respectivamente nos dias 24 e 31 de março e 08 de abril em cadeia nacional de rádio e televisão, há a exaltação da cloroquina como o medicamento capaz de prevenir e curar o coronavírus. Não há nenhuma menção ao uso de equipamentos de proteção individual, como máscaras, ou mesmo o uso de álcool em gel 70\%, como práticas e insumos eficientes de prevenção durante a pandemia (Bolsonaro recorre, 27/06/2020). Disse Bolsonaro em 24 de março:

Enquanto estou falando, o mundo busca um tratamento para a doença. O FDA americano e o Hospital Albert Einstein, em São Paulo, buscam a comprovação da eficácia da cloroquina no tratamento do Covid-19. Nosso governo tem recebido notícias positivas sobre este remédio fabricado no Brasil e largamente utilizado no combate à malária, lúpus e artrite. Acredito em Deus, que capacitará cientistas e pesquisadores do Brasil e do mundo na cura desta doença.

Uma semana depois, o Presidente afirma: "Vamos cumprir essa missão, ao mesmo tempo em que cuidamos da saúde das pessoas. O vírus é uma realidade, ainda não existe vacina contra ele, ou remédio com eficiência cientificamente comprovada, apesar da hidroxicloroquina parecer bastante eficaz" (Bolsonaro, 31/03/2020). Trata-se de uma tomada de posição explícita em favor do uso do referido medicamento enquanto estratégia de garantia da saúde, afirmando a eficiência e a eficácia do seu uso, inobstante deixando de indicar as evidências em que se baseiam suas afirmações.

É neste sentido que demos o título de "Cloroquina acima de tudo" para esta seção: o medicamento foi usado nas declarações do Presidente como a pílula mágica que resolveria o problema da pandemia no Brasil. E essa solução seria rápida, simples e barata, que resolveria a antítese entre proteção de vidas e garantia de empregos, conforme apresentado na seção anterior. As recorrentes referências à cloroquina como remédio eficaz e eficiente contra 0 coronavírus se articula à negação, por parte de Bolsonaro, em assumir a medida do distanciamento social como estratégia de prevenção. Isso porque o distanciamento de corpos e, no limite, o fechamento de fronteiras e divisas e consequente isolamento da população (lockdown) têm inegavelmente efeitos econômicos. Assim, esquivando-se de mencionar as medidas de distanciamento e, também, de uso de máscaras de proteção facial, o uso da cloroquina torna-se a pedra angular das declarações oficiais do Presidente.

Naquele mesmo pronunciamento, o Presidente afirma que "as consequências do tratamento não podem ser mais danosas que a própria doença. $O$ desemprego também leva à pobreza, à fome, à miséria, enfim, à própria morte" (Pronunciamento, 08/04/2020). E ele pensa, ainda, que sua posição tem amplo apoio popular, declarando ter "certeza de que a grande maioria dos brasileiros quer voltar a trabalhar" (Pronunciamento, 08/04/2020). Segundo Lazzarato (2019), existe uma relação entre fascismo e neoliberalismo que pode ser percebida a partir da relação de Hayek com o ditador chileno Augusto Pinochet. Tal relação promove o crescimento 
das chamadas "liberdades pessoais" (relacionadas a questões econômicas, como liberdade para comercializar, empreender, investir no mercado financeiro) às custas da "liberdade política" (sufocam-se os focos de resistência, calam-se as vozes dissidentes). É sobre este pano de fundo que podemos compreender as manifestações presidenciais contrárias a restrições econômicas, alegando a liberdade que cada um tem de produzir e gerar renda. Mesmo que esta liberdade custe sua vida ou de seus familiares. Atrelado a essa ideia de liberdade, o uso da cloroquina se adequa como alternativa mais simples (porque mais individualista) para solucionar o problema econômico do trabalho no Brasil.

As sucessivas declarações de Bolsonaro enaltecendo a cloroquina mesmo sem evidência de eficácia e eficiência, bem como a recusa em assumir o uso de equipamentos de proteção individual e o distanciamento social como medidas de prevenção, causaram crescente atrito com o então Ministro da Saúde, o médico Luiz Henrique Mandetta (Médico, 03/04/2020). A tensão entre o Presidente e o então Ministro chegou ao ápice em 06 de abril, quando Mandetta deixou explícitos os critérios segundo os quais orientava o trabalho de enfrentamento à pandemia feito pelo Ministério da Saúde: "Vamos fazer pela ciência. Ci-ência. Não vamos perder o foco. Ciência, disciplina, planejamento, foco. Ciência, disciplina, planejamento, foco" (Mandetta, 06/04/2020). Esse posicionamento contrasta vigorosamente com as declarações de Bolsonaro, e a situação periclitante de Mandetta no governo teve fim no dia 16 de abril de 2020, quando Nelson Teich foi anunciado como seu sucessor. Na cerimônia de posse de Teich, o Presidente afirmou voltou a sustentar que a prevenção ao coronavírus - isto é, a proteção da saúde da população - não poderia causar mais danos que a própria pandemia:

A visão do Mandetta, muito boa, é a da saúde e da vida. A minha também é a da saúde e da vida, mas entra também o Paulo Guedes, a economia e o emprego. Desde o começo eu tinha uma visão que nós devemos abrir o Brasil. O efeito colateral do combate ao vírus não pode ser, do meu ponto de vista, mais danoso do que o próprio remédio. (Em posse, $17 / 04 / 2020$ )

Trata-se de uma declaração bastante importante, pois mostra que entre a saúde e a vida existem a economia e o emprego - e, na eventual escolha entre essas alternativas, o Presidente brasileiro escolheria o "mercado acima de tudo". A vida e a saúde estão, nas declarações de Bolsonaro, submetidas à economia e ao comércio. A hierarquização manifesta entre economia e saúde, com preferência à primeira, ficou evidente quando o Presidente declarou o seguinte por ocasião do recorde de número de mortos por COVID-19 no Brasil, em 28 de abril de 2020: "E daí? Lamento. Quer que eu faça o quê? Ninguém nunca negou que teríamos mortes” (E daí, 28/04/2020).

As declarações do Presidente brasileiro expressam uma combinação entre biopolítica (Foucault, 2015; 2012) e necropolítica (Mbembe, 2018). A biopolítica, segundo Foucault, define-se como o poder sobre a vida humana, o governo do corpo da população pelos EstadosNação e suas instituições. Já a necropolítica, tal como proposta por Achille Mbembe (2018), aponta para outra direção, complementar ao governo biopolítico das populações: a morte se eleva como objetivo do poder por meio de um conjunto de estratégias que obstruem e negam condições dignas de vida, promovendo o terror e a degradação de grandes parcelas de humanos. Nessa direção, como Chefe da Nação, Bolsonaro afirmou que desde o início da 
pandemia se preocupou em proteger as vidas dos cidadãos brasileiros. Para isso, recorreu sistematicamente ao apoio explícito do tratamento com a cloroquina e prescindiu de apoiar e aderir, ele próprio, ao uso de máscaras. Por outro lado, priorizou a saúde econômica do país sobre a saúde biológica da população por meio de afirmações e atitudes que incitaram a recusa do isolamento e distanciamento sociais. Assim, preferindo retomar a atividade econômica em geral, Bolsonaro submeteu a vida dos cidadãos brasileiros ao imperativo do mercado, desprezando as milhares de mortes no país. Parece-nos possível depreender das declarações do Presidente aqui selecionadas que as vidas que importam (para ele e para o modelo de gestão que ele imprime ao país) são aquelas que mantêm a economia funcionando; uma vez perdidas para a doença, outras ocuparão seus postos no mercado, num permanente processo de substituição no qual a morte não só é naturalizada como é, também, promovida. Sustenta Jean Segata (2020, p. 277) a pandemia evidencia uma vulnerabilidade que se manifesta "na necropolítica das inúmeras formas de racismo, exclusão e violência estrutural, sobremaneira aquelas manifestadas no robusto projeto de denegação que tem sido protagonizado por governos que combinam o neoliberalismo e o emergente extremismo de direita, como é o caso do Brasil".

A disputa pela cloroquina se intensificou no mês de maio de 2020. Depois da substituição de Mandetta por Nelson Teich à frente do Ministério da Saúde, o Presidente continuou a afirmar que o medicamento seria a saída oficial para o país enfrentar a pandemia de COVID-19. Ele sustentou que "É o entendimento de muitos médicos do Brasil e outras entidades de outros países que a cloroquina pode e deve ser usada desde o início, apesar de saberem que não tem uma confirmação científica da sua eficácia", e completou: "temos este [medicamento] no Brasil aqui, que pode dar certo, pode não dar certo. Mas como a pessoa não pode esperar quatro, cinco dias para decidir, que a morte pode vir, é melhor usar" (Bolsonaro quer, 13/05/2020). A pressa pela incorporação da cloroquina no protocolo oficial de tratamento, no entanto, estava vinculada à urgência em retomar o fluxo de comércio e trabalho da economia brasileira. Na mesma declaração em que defende o uso sem evidências do medicamento, Bolsonaro afirmou que "quem ficar em casa parado vai morrer de fome, não podemos ficar hibernando em casa, tem que parar com essa babaquice", e terminou sua fala elevando a voz: "Quem não quiser trabalhar, fique em casa!" (Bolsonaro quer, 13/05/2020). Nesse contexto, a administração da cloroquina, mesmo em casos leves e iniciais da doença, supostamente permitiria os trabalhadores e consumidores e retomarem o comércio, a produção e o consumo.

Segundo Segata (2020), há uma correlação explícita entre a forma contemporânea do neoliberalismo e a pandemia de covid-19, na medida em que esse sistema econômico vem transformando as relações sociais, formas de produção, meios de transporte e comunicação. Consoante com Segata (2020), Diego Souza (2020) também analisa o cenário político e econômico do desenvolvimento do capitalismo de mercado como chave interpretativa sobre as transformações e desafios impostos pela pandemia. Para ele, trata-se de entender o processo de mediações unificadoras postas em ação pelo capitalismo global, que "não se resumem ao trânsito de pessoas e objetos, mas se referem a todo um estilo de vida, de cultura, filosofia, arte, de organização política etc. que espelham a dinâmica econômica" (Souza, 2020, p. 2474). Souza (2020, p. 2475) elenca entre os fatores de determinação social da pandemia "a prioridade dada à esfera econômica quando, sobretudo, evita-se obstáculos 
ao livre comércio, seja nacional, seja internacionalmente". É possível sugerir, com base nesses autores, que houve nos primeiros meses da pandemia no Brasil (sem dúvida, o mesmo poderia ser dito em relação aos países ocidentais como um todo) uma disputa de prioridades entre dois sentidos de saúde: a saúde biológica da população e a saúde econômica do mercado.

O posicionamento do Presidente em relação à cloroquina, que já havia provocado a demissão de Mandetta, continuou a tensionar o relacionamento com o novo Ministro Teich (Bolsonaro enquadra, 14/05/2020), levando-o a pedir demissão do cargo no dia 15 de maio de 2020. No dia 21 de maio, o Ministério da Saúde alterou o protocolo de uso da cloroquina, estendendo sua prescrição para casos leves da doença. Em uma transmissão ao vivo na rede social Facebook, segundo noticiado pelo jornal GaúchazH (Ministério, 20/05/2020), o Presidente deu a seguinte declaração: "O que é a democracia? Você não quer? Você não faz. Você não é obrigado a tomar cloroquina. Quem é de direita toma cloroquina. Quem é de esquerda toma Tubaína", afirmou com ironia, mencionando uma marca de refrigerante brasileiro.

Ao formular uma ironia sobre o uso do medicamento, articulando os espectros da direita e da esquerda, o Presidente evidenciou a disputa ideológica que orientou suas declarações acerca da pandemia de covid-19 no Brasil durante 2020. Ao afirmar que cidadãos de direita usariam cloroquina, Bolsonaro partidarizou a doença e seu tratamento, vinculando uma forma de tratamento a uma posição política. Além disso, estabeleceu uma cisão simbólica na própria saúde da população brasileira, na medida em que associa todos os supostos benefícios da cloroquina aos eleitores de direita eventualmente infectados com o COVID-19; já aos eleitores de esquerda eventualmente infectados, sugere que tomem um refrigerante - isto é, nenhum medicamento, nenhum tratamento.

Por meio de uma piada, o Presidente instaurou um corte simbólico entre aqueles cidadãos que mereciam o tratamento com a cloroquina - mesmo que seus benefícios não fossem comprovados - e aqueles que não mereciam o mesmo tratamento. Isso caracteriza a política de morte amiúde presente nas suas declarações, direcionada à esquerda política. Além da partidarização excludente, Bolsonaro ainda vinculou certa noção de democracia à adesão ao tratamento: segundo ele, democracia seria a liberdade de não fazer algo se não houver desejo de fazê-lo, que, nesse caso, era o uso da cloroquina. Remete-se, mais uma vez, à concepção neoliberal, individualista de democracia, que atravessou todos os posicionamentos do Presidente sobre as medidas de enfrentamento à pandemia. A ideia de que a prática democrática repousa na decisão individual de aderir ou não às estratégias de prevenção (uso de máscara, distanciamento e isolamento social, uso de álcool gel) e ao tratamento com a cloroquina desloca o aspecto coletivo intrínseco às formas de espraiamento do vírus e, por consequência, às formas também coletivas de surgimento, prevenção e mitigação da doença. Esse é um dos aspectos sustentados por Segata (2020, p. 303): "Em outras palavras, o que temos vivido com a Covid-19 é apenas mais um sintoma. A verdadeira doença ainda se chama capitalismo".

A pandemia de COVID-19, assim como outras que assolaram o Brasil recentemente - como as do zika e chikungunya -, explorou as fragilidades sociais constituintes do país e expôs a face mais cruel da desigualdade do neoliberalismo de mercado (Segata, 2020; Souza, 2020). O governo federal brasileiro, representado pelo Chefe do Executivo, assumiu publicamente sucessivas posições contraditórias sobre a pandemia, ora apostando na cura milagrosa da 
cloroquina, ora estimulando que a população brasileira se expusesse ao vírus o mais rápido possível para adquirir "imunidade de rebanho" (Cocco, 2020). Por isso, as declarações de Bolsonaro que minimizaram os crescentes números de infectados e mortos contribuíram na construção de uma política do verdadeiro negacionista, ambígua, anticientificista, orientada para preservação da saúde econômica do mercado em detrimento à saúde biológica da população brasileira - o que resultou na demissão de dois Ministros da Saúde dentro do período analisado.

\section{CONSIDERAÇÕES FINAIS}

Este artigo teve por objetivo analisar as políticas do verdadeiro em declarações do Presidente brasileiro Jair Bolsonaro durante os meses iniciais da pandemia no país. Para tanto, procedeuse ao arquivamento de 45 matérias jornalísticas publicadas no jornal digital GaúchazH nas quais as declarações eram reverberadas. Além disso, também foram analisados os três pronunciamentos oficiais do Presidente, realizados em março e abril de 2020. As análises orientaram-se pela análise de discurso, com base em Michel Foucault (2009), e as discussões foram tecidas à luz de autores contemporâneos que debatem as implicações políticas e sociais da pandemia.

Podemos circunscrever pelo menos cinco dimensões das políticas do verdadeiro a partir das declarações de Bolsonaro. Tomando a verdade, o saber e o poder como linhas entrelaçadas que constituem e circunscrevem o discurso, é possível apontar, primeiramente, que o Presidente brasileiro enunciou a verdade neoliberal, desocultando o mercado como organizador fundamental do seu discurso durante a pandemia no Brasil. Em segundo lugar, essa verdade do mercado repousa em uma concepção específica de liberdade e, consoante, de democracia: individualista, atomizada, definida pela (livre?) escolha de cidadãos isolados em fazer ou não fazer algo. O pilar dessa política do verdadeiro se expressou na insistência do Presidente em manter o comércio aberto, garantindo o fluxo de capital e o consumo, e opondo-se sistematicamente às medidas sanitárias de prevenção como o distanciamento e isolamento sociais.

Assim, em terceiro lugar, Bolsonaro apostou que o uso do medicamento cloroquina seria a solução mais rápida e simples para a pandemia - argumento apoiado na verdade do mercado, pois a "pílula mágica" garantiria a circulação dos cidadãos, salvaguardaria a saúde biológica da população e, também, a saúde econômica do país. Entretanto, e em quarto lugar, a cisão entre saúde econômica e saúde biológica foi claramente hierárquica: a primeira teve precedência sobre a segunda. Mesmo o uso da cloroquina era estimulado com o argumento do aquecimento da indústria farmacêutica doméstica. Finalmente, houve a explícita polarização ideológico-partidária nas políticas do verdadeiro enunciadas por Bolsonaro, na medida em que atribuiu diferentes formas de prevenção aos cidadãos de direita e aos de esquerda. $\mathrm{O}$ corolário cruel das suas declarações, que serve de conclusão deste artigo, foi de desprezar as mortes dos cidadãos brasileiros por COVID-19, explicitando que a verdade do mercado por ele defendida no funcionamento das políticas do verdadeiro é, também, uma política de morte.

Tendo em vista que o material utilizado foram as declarações até julho de 2020, com exceção de uma matéria de novembro, acreditamos que seja importante dar continuidade a esta pesquisa, analisando as continuidades e descontinuidades discursivas a partir daí. A versão final deste artigo é de março de 2021, momento em que o Brasil observa um catastrófico 
aumento da contaminação e, simultaneamente, o colapso de seu sistema de saúde. Apesar disto, Bolsonaro insiste em duvidar da eficácia das máscaras e do isolamento social, ao mesmo tempo que se posiciona de forma errática em relação à vacina e ao prolongamento do auxílio emergencial.

Além da continuidade desta pesquisa para abranger um maior período de tempo, outro possível desdobramento seria analisar como o Jornal ZH contribuiu para divulgar e consolidar determinadas verdades acerca da pandemia junto a seu público, com o objetivo de entender as políticas do verdadeiro deste veículo de comunicação.

\section{Referências}

Benetti, M. (2008). O jornalismo como gênero discursivo. Galáxia (15), 13-28.

Brasil (2020, 21 de agosto). Auxílio Emergencial chega a 60\% da população brasileira. https://bit.ly/3qrVyuJ.

GaúchaZH (2020, 15 de abril). Brasil leva 22 dias entre anúncio e início de pagamento de auxílio de $R \$$ 600. https://bit.ly/39vwXt7.

Brasil (2020). Senado Federal. Projeto de Lei $n^{\circ}$ 5495, de 2020. https://bit.ly/35JcpB5. Consultado em 23 de dezembro de 2020.

GaúchaZH (2020, 18 abril). Carreatas pelo país pedem fim do distanciamento social. https://bit.ly/3nlwY6T.

Carvalho, L. (2020). Curto-circuito: o vírus e a volta do Estado. Todavia.

Castilho, M. (2019). Palanque digital: as redes sociais como política de comunicação no governo Bolsonaro. Temática, (15)11, 145-159.

Castilho, M. (2020). O sistema de radiodifusão nos 100 primeiros dias do governo Bolsonaro. Revista ComPolítica, (10)1, 87-108. https://doi: 10.21878/compolitica.2020.10.1.292

Coco, G. (2020). Covid-19: a catástrofe latino-americana, entre a caça e a imaginação. Reciiis - Rev. Eletron. Comun. Inf. Inov. Saúde. (14)4, 812-819. https://doi: 10.29397/reciis.v14i4.2233

Souza, D. (2020). A pandemia de COVID-19 para além das Ciências de Saúde: reflexões sobre sua determinação social. Ciência \& Saúde Coletiva, (25), 2469-2477. https://doi: 10.1590/141381232020256.1.11532020

Do Val, G. y Aquino, J. (2013). A ordem do discurso jornalístico sobre educação: uma análise das matérias da Folha de S. Paulo de 1996 a 2006. Educação em Revista (29)1, 93-120. https://doi: 10.1590/S0102-46982013000100006

Foucault, M. (2009). A ordem do discurso. Loyola.

Foucault, M. (2014). Do governo dos vivos. Martins Fontes.

Foucault, M. (2000) Verdade e poder. In: Foucault, M. Microfísica do poder (pp. 1-14). Graal.

Lazzarato, M. (2019). Fascismo ou revolução? N-1.

Mbembe, A. (2018). Necropolítica. N-1.

Segata, J. (2020). Covid-19, biossegurança e antropologia. Horiz. Antropol. (26)57, 275-313. https://doi: 10.1590/S0104-71832020000200010

Singer, A.; Dunker, C.; Araújo, C; Loureiro, F; Carvalho, L; Paulani, L; Braga, R; Safatle, V. (2020, 03 de junho). Coronavírus reforça urgência da união de forças democráticas contra Bolsonaro. Folha de S. Paulo. https://bit.ly/2LyNk51.

Stanley, J. (2020). Como funciona o fascismo. L\&PM. 


\section{Matérias analisadas}

Após ignorar ministro, Bolsonaro diz ter vontade de baixar decreto para população poder trabalhar. GaúchaZH, 29 mar. 2020. Disponível em https://bit.ly/39yEjkn . Acesso em 23 dez. 2020.

Bolsonaro critica "desinformação e pânico disseminado" por causa da covid-19. GaúchaZH, 25 jun. 2020. Disponível em https://bit.ly/2XIs3lt . Acesso em 23 dez. 2020.

Bolsonaro diz que falta humildade a Mandetta, mas que não pretende demiti-lo. GaúchaZH, 02 abr. 2020. Disponível em https://bit.ly/39xMHkb . Acesso em 23 dez. 2020.

Bolsonaro diz ver excesso de preocupação com covid-19. GaúchaZH, 25 jun. 2020. Disponível em https://bit.ly/3qmFWZa . Acesso em 23 dez. 2020.

Bolsonaro enquadra Teich diz que Ministério da Saúde mudará o protocolo sobre cloroquina. Gaúcha ZH, 14/05/2020. Disponível em https://bit.ly/2LRjpoB . Acesso em 10 jan. 2021.

Bolsonaro quer ampliar o uso da cloroquina contra coronavírus apesar da falta de evidência. GauchazH, 13/05/2020. Disponível em https://bit.ly/3qlOEZt . Acesso em 10 de jan. 2021.

Bolsonaro recorre de decisão que o obriga a usar máscara. GauchaZH, 27/06/2020. Disponível em https://bit.ly/3bCtdxu . Acesso em 10 jan. 2021.

Bolsonaro responsabiliza governadores e prefeitos por combate ao coronavírus. GaúchaZH, 08 jun. 2020. Disponível em https://bit.ly/3bGn8Qs. Acesso em 23 dez. 2020.

E daí? Lamento, quer que eu faça o quê?, diz Bolsonaro sobre recorde de mortos por coronavírus. GaúchaZH, 28 abr. 2020. Disponível em https://bit.ly/39zTIGy . Acesso em 08 jan. 2021.

É Guerra, tem que jogar pesado com governadores. GaúchaZH, 14 maio 2020. Disponível em https://bit.ly/3oX3weE . Acesso em 23 dez. 2020.

Em posse de Teich, Bolsonaro defende abertura de fronteiras e comércio e critica governadores. GaúchaZH, 17 abr. 2020. Disponível em https://bit.ly/3soaxY9 . Acesso em 08 jan. 2021.

Governo muda estratégia após críticas de especialistas e deve liberar auxílio de R\$ 600 sem PEC. GaúchaZH, 01 abr. 2020. Disponível em https://bit.ly/3bFqH9R. Acesso em 23 dez. 2020.

Gripezinha: leia a íntegra do pronunciamento de Bolsonaro sobre covid-19. UOL, 24 mar. 2020. Disponível em https://bit.ly/2Ly2Dei . Acesso em 23 dez. 2020.

Mandetta diz que fica no Ministério da Saúde e reitera necessidade de isolamento social. GaúchaZH, 06 abr. 2020. Disponível em https://bit.ly/2XHzHms . Acesso 08 jan. 2021.

Médico não abandona paciente, diz Mandetta sobre eventual pedido de demissão. GaúchaZH, 03 abr. 2020. Disponível em https://bit.ly/2LL33xD . Acesso em 08 jan. 2021.

Ministério da Saúde muda protocolo e amplia o uso da cloroquina para casos leves. GaúchaZH, 20/05/2020. Disponível em https://bit.ly/2Klhng4 . Acesso em 10 jan. 2021.

Pronunciamento do presidente Bolsonaro em 31 de março de 2020. Blog do Esmael, 01 abr. 2020. Disponível em https://bit.ly/35Gz94y . Acesso em 23 dez. 2020.

Pronunciamento. Veja e leia na íntegra o pronunciamento de Jair Bolsonaro. UOL, 08 abr. 2020. Disponível em https://bit.ly/2N9cyYl . Acesso em 23 dez. 2020.

Tem que deixar de ser um país de maricas. GaúchaZH, 10 nov. 2020. Disponível em https://bit.ly/2LxEBQA. Acesso em 23 dez. 2020.

\section{Retrato dos autores}

Karla Saraiva é doutora em Educação (UFRGS), mestre e graduada em Engenharia Civil. Desenvolve pesquisas articulando educação, entendida de forma ampla, e questões relativas à organização sociopolítica contemporânea. É professora da Universidade Luterana do Brasil, onde atua nos cursos de licenciatura e no Programa de Pós-Graduação em Educação. 
Coordena o Grupo de Estudos Educação para a Revolta e a Insurgência (GEERI). É editora da Revista Textura (ULBRA).

Luiz Felipe Zago é doutor e mestre em Educação (UFRGS), bacharel em Comunicação Social Jornalismo. É pós-doutorando voluntário junto ao Programa de Pós-Graduação em Enfermagem da UFRGS, pesquisando saúde digital, promoção da saúde e comunicação e saúde. 